\section{Sense of rays}

\section{Richard L. Garwin}

Beam Weapons: The Next Arms Race. By Jeff Hecht.

Plenum: 1984. Pp.363. \$17.95, £17.10.

IN FEW areas of science and politics has public interest grown as rapidly as in that of directed energy weapons, especially as applied to space defence and anti-satellite attack. Key to this surge of awareness is President Reagan's speech of 23 March 1983 , in which he called for a research programme to "render nuclear weapons impotent and obsolete" by the ability to "intercept and destroy strategic ballistic missiles before they reached our own soil or that of our allies". Jeff Hecht's book was at the publisher's in draft form on that date, but the President's "Strategic Defense Initiative"' (SDI) (or "Star Wars") speech figures prominently in the updated text.

With a degree in electronic engineering from California Institute of Technology, and seven years as managing editor of Laser Focus, Hecht is well placed to interpret for a popular audience the development and potential of beam weapons that is, laser beams of infrared, visible or $\mathrm{X}$-radiation; charged or neutral particle beams of protons, electrons or hydrogen atoms; and beams of microwave radiation. He makes a valiant attempt to report myth as myth and fact as fact. Unfortunately the jobs of popularizer and decision-maker alike are seriously impeded by an unusual lack of substantive unclassified material from the United States Government on beam weapons, and by the confusion between, on the one hand, the President's call for a total defence as a result of a longterm research programme and, on the other, the warmed-over silo defence which is being offered at least as a mid-term goal of the SDI.

Hecht does a good job of distinguishing between weapons and systems, noting the easy integration of target acquisition, aiming, fire and damage assessment in the eye, brain and arm of the human archer or marksman, as contrasted with a system in which these functions are dispersed over many satellites and centres of control and responsibility. He also covers well the technological side of the subject, describing the early high-power gas dynamic lasers, chemical lasers such as those which produce light from the reaction of hydrogen and fluorine, and excimer lasers now powered by electron beams. He emphasizes properly the degree to which plumbing and ducting is required for bringing the reacting gases to a chemical laser, but perhaps does not recognize adequately the degree to which similar considerations are important in venting gas from excimer lasers, because of the inevitable retention of some $90 \%$ of the pumping energy in the gas.
A further attractive feature of the book is $\mathrm{Mr}$ Hecht's tone of good-humored scepticism, as in his observation that:

Pentagon officials have said that the Soviet effort [in laser weapons] is three to five times larger than the US program, an estimate that seems to hold constant even when the American budget is being sharply increased.

The treatment of the impact of space defence on national security is rather less solid. Hecht does not help to clarify matters by beginning with the "strategy of mutal assured destruction (MAD)" which, rather than being a strategy, is a fact of life. It is strategy to deter the opponent by threat of retaliation, but that one is able to do so and that one is deterred in return is a result of a technological fact - the destructiveness of nuclear weapons against societies and not so much a matter of choice.

Strategic options flow from technological capability, and only to a certain extent can technology be created in the service of strategy. For instance, the technology suitable for defence against strategic ballistic missiles is for the most part even more suitable in the destruction of those same defences. Hence the ambivalence (almost to the point of schizophrenia) of those favouring space defence over the problem of where to base the defending weapons. As Hecht notes, Edward Teller explicity recognizes that "it would be foolish to base a defensive system in space ... because satellites are costly to put up and cheap to shoot down". A weapon that could destroy a booster in a few seconds might readily be destroyed by comparable weapons launched with the booster or already in space, and yet to keep weapons on the ground until the attack is in progress presents insuperable difficulties for intercept during boost phase. Mr Hecht dismisses such "pop-up defence" as unlikely even for mid-course intercept, but proponents of boost-phase defence and X-ray lasers argue valiantly that even a 180 -s boost of an MX missile would be vulnerable to submarine-launched pop-up defence. Since the writing of this book, analysts have looked at countermeasures to some of the beam weapons, for instance fast-burn boosters to eliminate the threat of X-ray lasers or neutral-particle-beam weapons for boost-phase defence.

The issues surrounding beam weapons are at best murky and clear-thinking is not aided by statements of officials such as Dr George A. Keyworth, President Reagan's Science Adviser, who judges that:

we can approach the debate about strategic defense as either optimists or pessimists and still come to the same conclusion: We must proceed. The optimistic view would have the United States be the first to develop effective defensive capabilities, giving us a persuasive negotiating posture for arms reductions .... the pessimistic view sees the Soviets as the first to develop a real defensive capability .... [Aerospace America, April 1984].

Whatever the persuasive power of this argument, it has no foundation in logic: what about those technologists whose optimism is focused on penetration aids for defeating defences? No one doubts that starting from a conclusion one can find (some) arguments to support Keyworth's view, but in a democracy, and particularly when the questions involve not only hundreds of billions of dollars but the survival of nations, we need all the strength that open discussion and decision-making can provide. Beam Weapons will help to that end, together with the more extensive and technical Space-Based Missile Defense of March 1984 by the Union of Concerned Scientists, and especially the Background Paper by Ashton Carter, published in April 1984 by the Office of Technology Assessment.

In the book, Hecht displays a degree of constructive optimism and cites two possibly beneficial outcomes from beam weapons. One is "some sort of international peace-keeping organization to operate defensive satellites". The other is the hope that beam weapons "would tip the strategic balance of power to the defense", in providing missile defence, and "if the great powers can cope with the challenge of a transition to a strategic defense, the result could be a stabler world". I, however, would agree with the position taken by the French government in its presentation earlier this year (12 June) to the Committee on Disarmament in Geneva:

A situation in which each of the two principal powers sought to render its territory totally invulnerable, that is to say to escape any retaliation, without, however, being certain of being able to achieve this invulnerability, is fraught with danger:

On the one hand, the announcement itself of the intention to proceed with the creation of such systems constitutes itself an incitement to the acceleration of the offensive arms race: each power seeks to overcome (by saturation) the BMD [ballistic missile defence] systems envisaged by the other party, and in addition to increase greatly the number of non-ballistic carriers of nuclear weapons - notably cruise missiles.

Mr Hecht himself notes that the most credible role for a pop-up X-ray laser "is as part of a first-strike system, which would be put in place before the attack to defend against any enemy missiles which survived a massive first strike".

Beam Weapons is marred by misprints and by an irritating amount of repetition. Some references are quoted inaccurately, and the simple calculations provided would have been even more helpful had the arithmetical errors been corrected. But taken as a whole the book is a fair, readable attempt to make some sense out of the confusing claims and counterclaims about the feasibility and utility of directed energy in warfare.

Richard L. Garwin is IBM Fellow at the Thomas J. Watson Research Center, Yorktown Heights, New York, and Adjunct Professor of Physics at Columbia University. 